\title{
UKIRAN MOTIF ILIRAN PADA RUMAH AJI DI DESA ULAK PANDAN SEBAGAI SUMBER PEMBELAJARAN SEJARAH
}

\author{
Oleh: Karmila*, Aan Suriadi** \\ *Mahasiswa Program Studi Pendidikan Sejarah FKIP Universitas PGRI Palembang \\ ${ }^{*}$ Dosen Program Studi Pendidikan Sejarah FKIP Universitas PGRI Palembang
}

\begin{abstract}
ABSTRAK
Rumah Aji adalah rumah tradisional suku Aji di Ogan Komering Ulu yang memiliki kekayaan sejarah dan kebudayaan berupa ukiran yang dipahatkan di dinding dan tiang rumah. Permasalahan penelitian ini adalah nilai sejarah apa sajakah yang terkandung pada ukiran motif lliran pada rumah Uluan di desa Ulak Pandan yang dapat dijadikan sebagai sumber pembelajaran sejarah di Sekolah Menengah Atas (SMA) Negeri 16 Palembang. Tujuan penelitian ini untuk mengetahui nilai sejarah ukiran motif lliran rumah Uluan di desa Ulak Pandan yang dapat dimanfaatkan sebagai sumber pembelajaran sejarah. Metode yang digunakan dalam penelitian ini adalah metode deskriptif kualitatif. Teknik pengumpulan data adalah dokumentasi, observasi dan wawancara. Teknik analisis data yaitu reduksi data, sajian data, dan penarikan kesimpulan. Hasil penelitian: motif ukiran lliran memiliki kesamaan bentuk yang sama dengan rumah tradisional Iliran. Nilai sejarah ukiran motif Iliran dapat dijadikan sebagai sumber pembelajaran sejarah dan akan membantu siswa untuk mengenal ukiran motif Iliran, sehingga sebagai penerus bangsa siswa dapat lebih mencintai peninggalan sejarah lokal Sumatera Selatan.
\end{abstract}

Kata Kunci: Ukiran Motif lliran, Rumah Uluan, Sumber Pembelajaran sejarah.

\section{A. PENDAHALUAN}

Kebudayaan berkaitan dengan makna, nilai dan simbol. Pemahaman dinamika kebudayaan pada dasarnya memahami masalah makna, nilai dan simbol, yang dijadikan acuan oleh sekelompok masyarakat pendukungnya. Rumah tradisional pada umumnya sangat erat kaitannya dengan kosmologi masyarakatnya. Sebuah rumah identik dengan personifikasi sesuatu yang ada di alam seperti alam, tumbuhan, binatang, ataupun abstraksi dari sesuatu yang ada di alam (Akib, 1975:76). Adanya kosmologi tersebut erat kaitannya dengan tujuan hidup penghuni rumahnya yang mendambakan kesejahteraan, kesehatan, kedamaian selama mendiami rumah tersebut. Untuk mencapai tujuan tersebut maka di dalam rumah terdapat bagian-bagian tertentu yang di anggap sakral dan pemberian simbolsimbol sebagai penangkal hal-hal yang jahat yang terwujud dalam ragam hias (Arios,2012:52-53).
Proses pergeseran kebudayaan di Indonesia, khususnya di pedesaan, telah menyebabkan pergeseran wujud-wujud kebudayaan yang terkandung dalam arsitektur tradisional. Pembangunan yang giat dilakukan dewasa ini merupakan proses pembaharuan disegala bidang dan pendorongan utama terjadinya pergeseran-pergeseran dalam bidang kebudayaan, khususnya dibidang arsitektur tradisional. Pergeseran ini cepat atau lambat akan merubah bentuk struktur dan fungsi dari arsitektur tradisional. Kenyataan ini menjurus ke arah berubah atau punahnya arsitektur tradisional itu dalam suatu masyarakat (Hanafi, 1985:1).

Daerah Sumatera Selatan banyak memiliki aneka ragam unsur budaya. Keanekaragaman itu telah melahirkan berbagai bentuk, jenis dan corak seni budaya yang merupakan pencerminan segala sesuatu yang menyangkut aktivitas kehidupan masing-masing kelompok. Dalam arsitektur tradisional, terkandung secara terpadu wujud idea, wujud 
sosial dan wujud material suatu kebudayaan (Heryani,1993:1).

Rumah merupakan tempat tinggal manusia dan tempat untuk melakukan segala aktivitas sehari-hari. Sebagai tempat melakukan aktivitas sehari-hari, maka dibentuk sedemikian rupa untuk mendukung aktivitas tersebut dengan ciri penanda khas sebagai simbol kepemilikan kelompok mereka. Dengan simbol tersebut maka rumah tersebut menjadi sebuah karya budaya yang mereka cipatakan. Dengan alasan ini sudah barang tentu dibangun atau didirikan tidak secara sembarangan, selalu diikuti oleh ritual-ritual atau upacara-upacara tertentu yang biasanya bercorak magis, dengan maksud untuk keselamatan penghuni dan keluarganya serta tukang-tukang yang membangun rumah (Arios,2012:111).

Ragam hias di Sumatera Selatan sudah dikenal sejak masa pra-sejarah. Dimana pada masa itu ditemukan tinggalan budaya yang mewujudkan sudah adanya ragam hias, yaitu dengan ditemukannya bukti-bukti arkeologis pada batuan masa neolitikum, motif-motif seni ukir (ragam hias) telah menunjukkan pada sifat monumental dan simbolis. Perkembangan selanjutnya yaitu masa kebudayaan Dong Son, keterampilan seni ukir makin banyak ragamnya, demikian pula masa kerajaan Sriwijaya seni ragam hias muncul dan berkembang pada kain tenun, keramik dan sebaginya (Heryani,1993:26).

Diharapkan dengan penggunaan berbagai sumber dan observasi langsung ke lapangan tempat dimana rumah uluan berada pemahaman siswa dapat meningkat dan memahami secara langsung baik bentuk, motif, makna sejarah dan nilai seni yang terkandung di dalamnya. Dengan demikian sesuai uraian permasalahan dan teori yang diuraikan di atas, penulis tertarik untuk meneliti tentang "Ukiran Motif Iliran Pada Rumah Aji Di Desa Ulak Pandan Sebagai Sumber Pembelajaran Sejarah Di Sekolah Menengah Atas (SMA) Negeri 16 Palembang".

\section{B. METODE PENELITIAN}

Metode kualitatif deskriptif yaitu melakukan penelitian dengan melakukan penelitian untuk mengungkapkan fakta, keadaan, fenomena, variabel dan keadaan yang terjadi saat penelitian berjalan dan menyuguhkan apa adanya. Sumber data yang digunakan oleh peneliti seperti melalui sumber informan, arsip dan observasi langsung (Agung,2013:35).

\section{Teknik Pengumpulan Data}

Pengumpulan data dapat dilakukan dalam berbagai setting, berbagai sumber dan berbagai cara. Bila dilihat dari sumber datanya, maka pengumpulan data dapat menggunakan sumber primer dan sumber sekunder.Pengumpulan data berdasarkan tekniknya yaitu melalui studi kepustakaan, observasi, dan wawancara (Sugiono, 2013:3).

\section{Validitas Data}

Valaditas merupakan derajad ketepatan antara data yang terjadi pada obyek penelitian dengan daya yang dapat di laporkan oleh peneliti. Dengan demikina data yang valid adalah data "yang tidak berbeda" antar data yang dilaporkan peneliti dengan data yang sesungguhnya terjadi pada obyek penelitian (Sugiyono,2009:267). Untuk menguji kredibilitas data dilakukan triangulasi, triangulasi merupakan pengecekan data berbagai sumber cara dan berbagai waktu, dengan demikian terdapat triangulasi sumber dan metode (Sugiyono,2009:273).

\section{Teknik Analisis Data}

Analisis data yang dilakukan dalam penelitian ini yaitu menggunakan analisis model interaksi, Analisis model interaksi terdiri atas tiga jalur kegiatan yang terjadi secara bersamaan, yaitu reduksi data, penyajian data, dan penarikan kesimpulan/verifikasi. 


\section{HASIL DAN PEMBAHASAN}

\section{Ukiran Motif lliran Pada Rumah Aji di Desa Ulak Pandan}

Lokasi penelitian berada di desa Ulak Pandan kecamatan Semidang Aji kabupaten Ogan Komering Ulu, dengan ketinggian 90 meter di atas permukaan laut. Di desa Ulak Pandan terdapat beberapa rumah tradisional yang keberadaannya sampai saat ini masih terawat dengan baik, tidak hanya rumah Uluan di desa Ulak Pandan juga terdapat rumah Gudangan, dalam penelitian ini peneliti meneliti rumah Uluan, rumah Uluan yang pertama Cik Din dan kedua rumah Ibu Yuliana (Catatan observasi lapangan 08 Februari 2016 № 11).

Pada umumnya bangunan-bangunan rumah yang ada di desa Ulak Pandan terdiri dari rumah panggung berupa limas, Pasemah dan Gudangan. Atap bangunan rumah panggung berupa piramida dan juga berbentuk gudangan. Bahan bangunan rumah yang utama adalah kayu, yaitu kayu medang, unglen, tembesu. Kemudian bahan untuk atap sendiri yakni genteng yang terbuat dari tanah liat (Catatan observasi lapangan 08 Februari 2016 № 12).

Berdasarkan struktur bangunannya, rumah Limas dan Pasemah di desa Ulak Pandan adalah rumah panggung. Berikut deskripsi tentang rumah Limas dan rumah Pasemah dan peneliti akan mengulas tentang ukiran rumah gudangan yang terdapat pada rumah gudangan di desa Ulak Pandan, kecamatan Semidang Aji, kabupaten OKU, Provinsi Sumatera Selatan yaitu:

\section{Ukiran Rumah Gudangan}

Rumah gudangan yang dimiliki ibu Nasimah merupakan salah satu rumah tradisional yang dimilki Provinsi Sumatera Selatan khususnya desa Ulak Pandan, secara keseluruhan bangunan rumah gudangan ini menggukan kayu-kayu pilihan yang tersedia di wilayah kecamatan Semidang Aji. Kayu-kayu yang digunakan pada rumah gudangan ini memiliki kualitas tinggi, hal ini dapat dilihat dari kondisi rumah walaupun usia rumah sudah mencapai hampir seratus tahun namun bangunan rumah ini masih tetap utuh (Catatan observasi lapangan, 08 Februari 2016 № 13).

Pada garang (Lintot) rumah gudangan memiliki dinding dengan motif jaring dan motif kelelawar, dinding pada teras ini dibagi menjadi dua yakni dinding bawah (Jeraw Bawah) dan dinding bagian atas (Jeraw Atas). Panjang dinding bawah (Jeraw Bawah) 7,5 Meter, tinggi $70 \mathrm{~cm}$. Dinding bawah (Jeraw Bawah) memiliki motif seperti Jaring (Catatan observasi lapangan 08 Februari 2016 № 15).

Pada dinding atas (Jeraw atas) memiliki motif seperti kelelawar yang bergantung panjang dinding atas sama seperti diding bawah yakni 7,5 Meter dan tinggi $85 \mathrm{~cm}$. Fungsi dari dinding atas (Jeraw atas)ini selain untuk memperindah tampilan teras (Lintont) juga untuk melindungi masuknya embunan air hujan agar tidak membasahi teras (Catatan observasi lapangan 08 Februari 2016 № 16).

\section{Ukiran Rumah Aji}

Rumah Uluan atau rumah Aji ialah salah satu rumah yang terdapat di desa Ulak Pandan rumah Uluan ini merupakan ciri khas Palembang, dengan atap induk rumah berbentuk piramida yang agak curam melebihi 45 derajat. Penutup atap semuanya dari genteng sedangkan atap adalah konstruksi kayu. Jenis bangunan ini merupakan rumah tinggal dari Cik Din (Catatan observasi lapangan 08 Februari 2016 № 17).

Pada tiang garang terdapat 6 corak ukiran yang berbeda dan mempunyai makna tersendiri yang terdapat pada rumah Cek Din di desa Ulak Pandan yaitu :

Motif bunga mawardilambangkan sebagai penawar baik penawar rasa sakit maupun penawar rasa rindu.

Motif wajik atau bubur talam yang pada dasarnya merupakan garis-garis zig-zag beraturan yang membentuk jajaran genjang.

Motif ukiran ini paku kayu yang melambangkan semangat juang yang tidak kenal menyerah.

Motif daun bunga teratai menggambarkan delapan jalan akhir derita nirwana, yaitu menjauhkan diri dari kehidupan duniawi, 
bertabiat ramah, pasrah, berkemanusiaan, menguasai kitab-kitab sastra, memiliki keberanian, memberi teladan berbuat baik dan tekun.

Motif tumpal atau pucuk rebung melambangkan sebuah pesan agar orang hidup hendaknya berguna, sebagimana pucuk rebung, yakni tunas bambu yang dapat tumbuh menjadi rumpun bambu dan berguna bagi manusia (Pertumbuhan).

Motif sulur-suluran dilambangkan kehidupan terus menerus.

Motif renda-renda.

Motif kalpataru suatu kehidupan yang begitu indah dan makmur.

Ukiran bagian peminggang yang terdapat pada dinding sebelah kanan rumah ini berbentuk persegi delapan dengan panjang $8,26 \mathrm{~cm}$ dan berdiameter $50 \mathrm{~cm}$. Pada bagian pinggir peminggan, baik pada bagian kanan dan kiri samping terdapat ukiran dengan bentuk bunga mawar. Bunga mawar dilambangkan sebagai penawar baik penawar rasa sakit maupun penawar rasa rindu. Ukiran ini berdiameter $5 \mathrm{~cm}$ dan ketebalan $1 \mathrm{~cm}$. Pada bagian tengahnya terdapat ukiran berbentuk motif wajik atau bubur talam dengan isiannya bunga mawar dengan panjang $7 \mathrm{~cm}$, lebar $3,5 \mathrm{~cm}$ dan tebal $1 \mathrm{~cm}$. Sedangkan pinggir-pinggirnya baik bagian kiri dan kanan atas maupun bawah diberi ukiran dengan motif menyerupai renda. Motif renda mempunyai tinggi $1 \mathrm{~cm}$ dan ketebalan $1 \mathrm{~cm}$ (Catatan observasi lapangan 08 Februari 2016 No 19).

Ukiran ini terdapat pada bagian atas tiang dengan ukiran paku kayu. Ukiran ini mempunyai tinggi $9 \mathrm{~cm}$, lebar bagian atas $10 \mathrm{~cm}$ dan lebar bagian bawah $8 \mathrm{~cm}$. Sedangkan pinggirpinggirnya diberi ukiran dengan motif menyerupai renda. Motif ukiran ini paku kayu yang melambangkan semangat juang yang tidak kenal menyerah (Catatan observasi lapangan 08 Februari 2016 № 20).

Ukiran ini terdapat pada bagian kedua mempunyai tinggi $3 \mathrm{~cm}$ dan lebar $10 \mathrm{~cm}$. Motif daun bunga teratai menggambarkan delapan jalan akhir derita nirwana, yaitu menjauhkan diri dari kehidupan duniawi, bertabiat ramah, pasrah, berkemanusiaan, menguasai kitab-kitab sastra, memiliki keberanian, memberi teladan berbuat baik dan tekun (Catatan observasi lapangan 08 Februarai 2016 № 21).

Ukiran pada bagian ketiga memiliki motif tumpal atau pucuk rebung dengan isian sulursuluran. Ukiran di atas berposisi tegak atau ujungnya di atas dan motif yang dibuat terbalik atau ujungnya dibawah. Ukiran pada bagian atas mempunyai tinggi $24 \mathrm{~cm}$, lebar bagian atas tupal $10 \mathrm{~cm}$ dan bagian bawah $8 \mathrm{~cm}$. Sedangkan ukiran bagian bawah mempunyai tinggi $25 \mathrm{~cm}$ dan lebar $8 \mathrm{~cm}$ (Catatan observasi lapangan 08 Februarai 2016 № 22).

Motif tumpal atau dalam istilah setempat disebut motif pucuk rebung berbentuk segitiga sama kaki. Bidang-bidang segitiga itu biasanya membentuk pola berderet yang kerapkali digunakan sebagai ornament tepi. Dalam berbagai variasinya, motif tumpal yang berbentuk dasar segitiga sama kaki disi oleh aneka motif tumbuh-tumbuhan. Motif pucuk rebung melambangkan sebuah pesan agar orang hidup hendaknya berguna, sebagimana pucuk rebung, yakni tunas bambu yang dapat tumbuh menjadi rumpun bambu dan berguna bagi manusia (Sunaryo, 2009:30).

Ukiran ini pada tiang garang bagian bawah yang mempunyai motif sulur-suluran dengan panjang $10 \mathrm{~cm}$ dan lebar $5 \mathrm{~cm}$. Motif Sulur-suluran melambangkan kehidupan terus menerus. Sedangakan pinggirnya di ukir dengan motif renda-renda (Catatan observasi lapangan 08 Februari 2016 № 23).

Bentuk ukiran motif pohon kalpataru atau pohon hayat. Ukiran kalpataru yang terdapat pada tiang rumah juga di hiasai dengan motif tumbuh-tumbuhan yang menjalar lebih dikenal dengan motif sulur-suluran atau pakis. Jika di lihat ukiran tersebut terdapat dua bagian yang berbeda, pada bagian atas ukiran bermotif seperti bunga yang mulai mekar dan dihiasi dengan sulur-suluran. Sedangkan pada bagian bawah motif dihiasi dengan bunga yang di kelilingi dengan motif sulur-suluran (Catatan observasi lapangan 08 Februari 2016 № 24). 
Dari hasil penelitian ukiran di atas bahwa pada ukiran yang terdapat pada tiang rumah memiliki makna yaitu pada ukiran paling atas menggambarkan suatu kehidupan yang begitu indah dan makmur karena selain di gambarkan dengan motif bunga-bunga yang mulai mekar juga di hiasi dengan sulur. Sulur sendiri bermakna banyak kehidupan. Pada ukiran bawah, menggambarkan suatu cara penerus kehidupan selanjutnya karena pada ukiran tersebut digambarkan dengan motif bunga yang di kelilingi motif sulur-suluran seolah-olah seperti di dalam lingkaran dan mati di lindungi "Belum Mekar".

\section{Ukiran Rumah Ulu}

Rumah kedua ini yaitu rumah ibu Yuliana, dengan atap induk rumah berbentuk piramida yang agak curam melebihi 45 derajat. Pada rumah kedua ukiran motif iliran terdapat pada bagian dinding rumah dan pada sisi pintu. Pintu yang pada rumah kedua berdaun pintu ganda. Corak ukiran yang terdapat pada rumah ini yaitu:

Bunga Matahari dilambangkan kehidupan, karena manusia tidak bisa hidup tanpa sinar matahari.

Bunga Teratai melambangkan keindahan juga merupakan ucapan selamat datang. Motif teratai atau lotus yang diukir masih memiliki tangkai melambangkan pemilikrumah selalu menghormati tamu yang datang atau bagaikan raja.

Motif sulur-suluran dilambangkan kehidupan terus menerus. Ukiran pada sisi pintu kiri dan kanan bermotif bunga teratai juga dihiasi dengan motif atau ukiran pakis sedangakan pinggirnya di ukir dengan motif renda-renda, serta bunga teratai yang diukir lengkap dengan tangkainya. Ukiran ini mempunyai tinggi 1,38 meter dan lebar $12,5 \mathrm{~cm}$. Nilai filosofi yang terdapat pada ukiran sisi pintu ini yaitu bunga teratai melambangkan keindahan juga merupakan ucapan selamat datang, oleh karena itu motif atau ukiran diletakkan di samping atau di sisi pintu. Selain itu motif teratai atau lotus yang diukir masih memiliki tangkai melambangkan pemilik rumah selalu menghormati tamu yang datang atau bagaikan raja, karna bisa kita lihat bunga teratai yang di akhir seperti diangkat dengan tangkainya atau disangga (Catatan observasi lapangan 08 Februari 2016 No 26).

\section{PEMBAHASAN}

Rumah Uluan adalah rumah tradisional masyarakat Uluan Sumatera Selatan. Rumah warga ini memiliki ukuran yang besar, sedang dan kecil, dengan kualitas bahan yang bervariasi. Rumah kelas atas memiliki ukuran besar dengan kayu kelas 1 yang dihiasi dengan ornamen ukiran dengan motif berbunga dan daun yang dilengkapi dengan hiasan geometris. Sehingga menjadi daya dukung ekonomi wilayah Komering pada masa lampau adalah dari sektor hasil kehutanan, pertanian, dan perkebunan. Damar merupakan komoditas utama dalam perdagangan wilayah Uluan dengan Iliran. Damar merupakan bahan bakar utama untuk kebutuhan penerangan rumah tangga dan kebutuhan kosmetik. Komoditas lainnya adalah getah gambir, biji pinang, beras dan ternak (Idris dan Sukardi, 2015:55). Adapun fungsi bagian-bagian rumah Uluan yang terdapat di desa Ulak Pandan kecamatan Semidang Aji Kabupaten Ogan Komering Ulu sebagai berikut:

Tiang adalah penyangga bangunan rumah yang terbuat dari kayu pilihan, berbentuk lingkaran bertingkat. Tiang-tiang utama berukuran lebih besar, adapun untuk tiang-tiang tambahan berukuran lebih kecil. Ketinggian dari tanah membentuk panggung yang bervariasi disesuaikan dengan kebutuhan. Ketinggian panggung memisahkan lantai rumah dengan tanah atau air di bawahnya, sehingga rumah terhindar dari banjir dan hewan liar.

Tangga (Tangge). Tangga pada rumah Uluan sering disebut dengan ljan. Tanggaberfungsi sebagai pijakan untuk menaiki rumah. Jumlah anak tangga biasanya ganjil atau genap.

Lintut (Garang). Setelah naik tangga, maka ruangan pertama yang dijumpai adalah 
garang, yaitu ruangan terbuka yang diberi pagar. Garang biasanya dipergunakan untuk duduk-duduk santai oleh anggota keluarga. Garang juga digunakan untuk menerima tamu yang masih bujang atau tetangga dekat. Tamu yang masih asing juga diterima ditempat ini.

Pintu (Lawang). Pintu pada rumah Uluan sering disebut dengan rawang. Pintu adalah lubang untuk jalan masuk dan keluar rumah berbentuk persegi panjang. Pintu terbuat dari papan kayu tidak menggunakan engsel. Sebelum melewati pintu utama, terdapat pagar yang di pasang didepan pintu yang disebut dengan jarau.

Haluan-kakudan. Ruang haluan-kakudan merupakan ruang keluarga. ruang ini dipergunakan untuk memenuhi beberapa fungsi antara lain untuk menerima tamu, pada ruangan ini tidak disediakan meja kursi. para tamu duduk diatas lantai berbahan dasar bilah yang sering kali dibentangkan tikar lampit atau kasha, yaitu sejenis tikar yang terbuat dari anyaman rotan. Ruang haluan ini juga digunakan untuk menampung aktifitas adat, kebudayaan dan agama. Ruang ini juga digunakan untuk meletakkan mayat apabila ada salah satu anggota keluarga yang meninggal dunia. Pada umumnya mayat diletakkan pada ruang haluan sebelum dibawa kepemakaman. Pada saat ada acara perkawinan kedua mempelai duduk diruang ini untuk melangsungkan akad nikah. Pada ruangan ini biasanya terdapat lemari kayu dan ranjang besi. Ranjang besi biasanya digunakan sebagai tempat tidur anak laki-laki (Abdullah,1995:99).

Kamar (Bada Tidok). Kamar merupakan ruangan pribadi yang berfungsi sebagai tempat tidur keluarga. Pada ruangan kamar lantainya tebuat lebih tinggi dari ruangan lainnya. Ruangan kamar ini biasanya terdapat dua atau tiga ruang. Pada masing-masing pintu kamar dibuat lankahan. Seluruh anggota keluarga kecuali anak bujang dapat tidur didalam kamar.

Dapur (Pawon). Dapur pada rumah uluan disebut juga dengan pawon. Pawon digunakan untuk melakukan kegiatan keseharian seperti memasak, mencuci piring, dan kegiatan kewanitaan lainnya. Oleh karena itu berbagai macam perlengkapan memasak terdapat diruangan pawon. Peralatan dan perlengkapan itu antara lain : periuk, singkup (untuk tutup membuat kue), kuali, cerek, kukuran (parut kelapa), batu penyaring air minum, rak piring yang terbuat dari kayu, tungku, dan sebagainya.

Jendela (Lawang kecek). Jendela adalah lubang untuk masuknya cahaya serta tempat sirkulasi udara yang bisa dibuka dan ditutup. Daun jendela pada rumah Uluan terbuat dari papan kayu dipasang secara vertikal, dan terdapat dua bukaan. Pada rumah Uluan biasanya tidak terdapat lubang angin sebagai tempat sirkulasi udara,yang menjadi tempat sikulasi adalah jendela dan pintu utama.

Lantai (gladak). Lantai terbuat dari papan, pemasangan papan lantai ini menyamping kekanan dan kekiri ruang rumah.

Dinding adalah bagian rumah yang berfungsi sebagai penutup ruang atau penyekat atau pelindung rumah dengan alam sekitar. Dinding rumah Uluan ini dibuat dari papan yang dipasang rapat dalam posisi membujur atau melintang.

Flafon berfungsi menahan bintik-bintik hujan yang masuk dari atap. Panaku ini juga digunakan untuk menyimpan barang-barang yang berguna.

Atap (Bubungan). Atap adalah penutup atas pada bagian rumah yang berfungsi melindungi rumah dari sengatan sinar matahari dan hujan. Atap pada rumah Uluan ini menggunakan bahan dari genteng atau seng.

Tiber angin (Tibing layar). tutup pada bidang segitiga atap pada bagian atas samping kanan dan kiri rumah yang berfungi sebagai penahan hempasan angin dan hujan yang masuk kedalam rumah melalui sisi kiri atau kanan rumah.

Tanduk kambing, yaitu berupa kayu berbentuk silang yang dipasang dibagian atap atap rumah dan berfungsi sebagai penahan atap rumah seperti genteng dan seng agar tidak jatuh tertiup angin. 
Hasil observasi yang dilakukan di desa Ulak Pandan Kecamatan Semidang Aji Kabupaten OKU, ditemukan bahwa ragam bentuk rumah uluan bentuk Arsitektur adalah rumah panggung, rumah Uluan di desa Ulak Pandan yang peneliti teliti berjumlah empat rumah yang masih mempertahankan bentuk aslinya. Pada rumah Uluan terdapat pengaruh dalam aspek pelestarian lingkungan. Aspek pelestarian lingkungan dapat di uraikan sebagai berikut :

Bahan-bahan yang digunakan dalam pembuatan rumah Uluan merupakan bahan dari alam yang ramah lingkungan, contohnya tiang yang digunakan berbahan dasar kayu. Pembuatan rumah Uluan tidak menggunakan bahan-bahan kima yang akan menyebabkan pencemaran, terutama pencemaran tanah. Dengan demikian, kerusakan lingkungan dapat diminalisir.

Penggunaan kayu yang baik sebagai bahan pembuat rumah Uluan dapat meminimalisir penebanagan pohon di hutan. Hal ini dikarenakan kayu yang digunakan adalah kayu yang tidak mudah lapuk, sehingga dapat bertahan dari generasi ke generasi berikutnya.

Rumah Uluan berbentuk panggung dapat meminimalisir tinggi banjir walaupun dalam satu wilayah terdiri dari rumah Uluan yang banyak. Hal ini dikarenakan rumah Uluan berdiri diatas tiang-tiang yang tinggi dan tiang rumah berdiri diatas batu-batu besar yang berfungsi agar dapat mengurangi getaran pada saat terjadi gempa bumi. Dengan tingginya tiang rumah apabila terjadi banjir, maka luapan air dapat mengalir melalui bawah rumah.

\section{Ukiran Motif lliran Pada Rumah Uluan di Desa Ulak Pandan sebagai Sumber Pembelajaran Sejarah}

Desa Ulak Pandan secara geografis merupakan salah satu desa yang terletak di kecamatan Semidang Aji Kabupaten Ogan Komering Ulu (OKU) yang dikelilingi perbukitan hal ini disebabkan karena keadaan alam yang tidak seragam oleh sebab itu daerah ini termasuk daerah perbukitan (daratan tinggi).
Desa Ulak Pandan merupakan daerah tinggi bebatuan dimana di dalam desa terdapat sebuah sungai besar (sungai Ogan) yang mengalir dari bukit Barisan sebagai sumber mata air menuju ke Hilir dan bermuara di sungai Musi tepatnya di daerah Kertapati, Palembang dan menjadi denyut nadi bagi segala aktivitas masyarakat di kabupaten Ogan Komering Ulu, sungai Ogan pada umumnya di desa Ulak Pandan digunakan sebagai sarana transportasi oleh penduduknya dan sebagai jalur perdagangan (Catatan wawancara 08 Februari 2016 No 27).

Keadaan topografi atau ketinggian wilayah Desa Ulak Pandan sekitar 90 diatas permukaan laut, mayoritas suku penduduk Desa Ulak Pandan adalah suku Ogan sebagian besar pendudukan Desa Ulak Pandan bermata pencarian sebagian perdagang, pertanian, kebun dan sawah. Salah satu hasil dari perdagangan pada waktu itu yaitu damar. Damar merupakan salah satu tanaman kayu asli Indonesia yang tersebar di Sumatera, Kalimantan, Sulawesi, Maluku dan Papua. Damar biasanya dimanfaatkan kayunya karena mempunyai nilai jual yang cukup tinggi, terutama digunakan untuk pertukangan. Pulp dan kayu lapisnya termasuk golongan awet IV dan awet III dengan berat jenis kayunya sekitar 0,49 . Nama damar sendiri diambil karena pohon ini memproduksi kopla (getah) atau yang biasa kita sebut dengan "damar".

Dari perdagangan ini daerah tersebut mengalami kemajuan sehingga penduduk setempat memiliki rumah-rumah yang besar. Rumah merupakan tempat tinggal manusia dan tempat untuk melakukan segala aktivitas sehari-hari. Sebagai tempat melakukan aktivitas sehari-hari, maka dibentuk sedemikian rupa untuk mendukung aktivitas tersebut dengan ciri penanda khas sebagai simbol kepemilikan kelompok mereka. Dengan simbol tersebut maka rumah tersebut menjadi sebuah karya budaya yang mereka cipatakan. Dengan alasan ini sudah barang tentu dibangun atau didirikan tidak secara sembarangan, selalu diikuti oleh ritual-ritual atau upacara-upacara tertentu yang 
biasanya bercorak magis, dengan maksud untuk keselamatan penghuni dan keluarganya serta tukang-tukang yang membangun rumah (Arios, 2012:111).

Menurut narasumber Senin Pada awal mulanya kehidupan sosial masyarakat Desa Ulak Pandan hanya berdiri 10 rumah saja, orang yang pertama kali membangun rumah adalah Puyang Sembawe Sakti ia adalah orang yang membangun perkampungan atau desa disana. Setelah itu memasuki masa koloni Belanda sampai awal Indonesia merdeka masyarakat desa Ulak pandan berada pada administrasi pemerintahan kepasirahan Tubuan. Pada masa koloni Belanda lebar jalan desa Ulak Pandan dengan lebar jalan hanya kurang lebih 3 meter yang diperkuat dengan batuan sungai (Catatan wawancara 08 Februari 2016 No 28). Setelah masa kepesirahan sampai sekarang kehidupan sosial masyarakat desa Ulak Pandan berkembang dengan pesat pemukiman atau rumah penduduk telah ramai di sepanjang jalan raya bagian utara desa yang tidak jauh dari sungai Ogan berdominasi rumah penduduk tipe lama seperti jenis rumah Uluan, gudangan (Catatan wawancara 08 Februari 2016 No 29).

Di desa Ulak Pandan kecamatan Semidang Aji kabupaten Ogan Komering Ulu memiliki banyak sekali ragam bentuk rumah Uluan diantaranya rumah Aji, rumah Basemah, dan rumah Gudangan. Ukiran adalah suatu cetusan dari penjelmaan dari rasa indah, kagum, gembira dan sedih. Motif adalah unsur pokok sebuah ornament, yang menurut hasil wawancara dengan bapak $M$. Senin yang menyatakan bahwa rumah-rumah yang ada di desa Ulak Pandan adalah rumah tradisonal rumah lliran yang dibeli langsung dari daerah lliran dan dibawa melalui jalur air dan darat dengan cara membeli rumah bongkar pasang dan juga ada yang membuat rumah langsung di daerah Uluan. Tukang atau yang membuat rumah didatangkan dari daerah lliran sehingga motif atau bentuk rumah di desa Ulak Pandan ini semuanya memiliki bentuk yang sama dengan rumah tradisonal Iliran (Catatan observasi lapangan 08 Februari 2016 № 30).
Desa Ulak Pandan mempunyai manfaat yang penting bagi pengembangan sumber pembelajaran sejarah, sebab di daerah ini banyak sekali ditemukan rumah-rumah sejarah dan budaya masa lampau. Sehingga sangat menarik untuk dijadikan sebagai sumber pembelajaran sejarah lokal. Dari uraian di atas maka dapat disimpulkan peluang bagi mahasisawa tersedianya sumber penelitian sejarah lokal sebuah rumah tradisional di desa Ulak Pandan dapat dijadikan sumber ilmu pengetahuan dan sumber pembelajaran sejarah bagi para guru sekolah menengah atas yang sebelumnya belum mengetahui secara baik kegunaan dan manfaat dari ukiran motif Iliran pada rumah Uluan. Bagi masyarakat setempat mereka dapat mengenalkan warisan sejarah berupa rumah tradisional yang dimiliki masyarakat luas pada umumnya dan masyarakat setempat pada khususnya serta lembaga pemerintahan daerah lembaga pemerintahan kota.

\section{SIMPULAN}

Bersadarkan hasil penelitian penelitian dan pembahasan tentang ukiran motif Iliran pada rumah Aji di desa Ulak Pandan penulis menarik kesimpulan sebagai berikut:

Ukiran motif lliran pada rumah Aji di desa Ulak Pandan merupakan ukiran motif rumah tradisional yang dibeli langsung dari daerah lliran dibawah melalui jalur air dan darat dengan cara membeli rumah bongkar pasang.Tukang atau yang membuat rumah adalah tukang yang didatangkan langsung dari daerah Iliran sehingga ukiran motif lliran atau bentuk yang sama dengan rumah tradisional lliran, seperti rumah Aji.

Ukiran motif lliran ada pada Standar Kompotensi: 1. Menganalisis perjalanan bangsa Indonesia dari negara tradisional, kolonial, pergerakan kebangsaan, hingga terbentuknya negara kebangsaan sampai proklamasi kemerdekaan Indonesia. Sedangkan Kompotensi Dasar: 1.1 Menganalisis perkembangan negara tradisional (HinduBuddha dan Islam) di Indonesia. Materi 
pembelajaran Menganalisis perjalanan bangsa Indonesia dari negara tradisional, kolonial, pergerakan kebangsaan, hingga terbentuknya negara kebangsaan sampai proklamasi kemerdekaan Indonesia karena ukiran motif liran di desa Ulak Pandan dapat disesuaikan dengan SK dan KD di atas.

\section{DAFTAR PUSTAKA}

Agung, Leo, dkk. 2013. Perencanaan Pembelajaran Sejarah. Yogyakarta: Ombak

Akib, Moehammad. 1975. Sejarah dan Kebudayaan Palembang: Rumah Adat Limas Palembang. Palembang: Universitas Sriwijaya.

Arios, Rois Leonard, Ernatp, Refisrul. 2012. Bunga Rampai Budaya Sumatera Selatan:Budaya Basemah di Kota Pagar Alam. Sumatera Barat: BPSNT Padang Press.

Hanafi, dkk, 1985.Arsitektur Tradisional Daerah Bengkulu. Jakarta: Departemen Pendidikan dan Kebudayaan Proyek
Inventarisasi dan Dokumentasi Kebudayaan Daerah.

Heryani, Yenny, 1993.Gelar Kebangsawanan Kaitannya dengan Rumah Limas Palembang. Palembang: Departemen Pendidikan dan Kebudayaan Direktorat Jenderal Kebudayaan Bagian Proyek Pembinaan Permuseuman Sumatera Selatan Tahun 1993/1994.

Saleh, Abdullah, dkk. 1995. Diskripsi Seni Ukir Palembang dan Sekitarnya. Palembang: Departemen Pendidikan dan Kebudayaan Kantor Wilayah Propinsi Sumatera Selatan Bagian Proyek Pembinaan Kesenian Sumatera Selatan Tahun 1995/1996.

Sugiyono. 2009. Metode Penelitian Kuantitatif, Kualitatif dan R\&D. Bandung: Alfabeta. 2013. Metode Penelitian Kuantitatif, Kualitatif dan R\&D. Bandung: Alfabeta.

Sunaryo, Arya. 2009. Ornamen Nusantara: Kajian Khusus tentang Ornamen Indonesia. Semarang: Dahara Prize. 